\title{
ADESÃO AO RASTREAMENTO DO CÂNCER DE COLO DE ÚTERO NA POPULAÇÃO TRANS: REVISÃO INTEGRATIVA
}

\author{
Alice Tavares da Mota, ${ }^{\prime}$ Denisson dos Santos Andrade, ${ }^{2}$ Fernanda Costa Martins Gallotti, ${ }^{3}$ Fernanda Dantas \\ Barros, ${ }^{4}$ Letícia Freire Gonzaga, ${ }^{5}$ Luanna Feitosa, ${ }^{6}$ Taciana Silveira Passos ${ }^{7}$
}

ADHERENCE TO THE CERVIX CANCER SCREENING IN THE TRANS POPULATION: AN INTEGRATIVE REVIEW

\section{ADHESIÓN AL SEGUIMIENTO DEL CÁNCER DE CUELLO UTERINO EN LA POBLACIÓN TRANS: UNA REVISIÓN INTEGRATIVA}

Resumo: O câncer do colo do útero é um dos mais comuns entre aqueles que apresentam o aparelho reprodutor feminino. No entanto, é prevenível e tratável, mas há uma dificuldade de captação do público-alvo bem como baixa adesão ao rastreamento na periodicidade adequada mesmo na população feminina cisgênero, sendo esta dificuldade acentuada entre os transexuais. Por isso, este artigo objetivou analisar a realidade da população transexual, em especial dos homens trans, buscando identificar as experiências, dificuldades e necessidades destes quanto à adesão ao exame citopatológico para rastreamento do câncer de colo de útero na Atenção Primária através de uma revisão integrativa com busca realizada em três bases de dados: Scopus, ScienceDirect e PubMed, sendo obtida uma amostra de oito artigos para a composição deste estudo. Os resultados mostraram que os usuários trans procuram bem menos o serviço de saúde quando comparado ao público heterossexual/cisgênero, tanto pela abordagem, manejo e falta da relação paciente-profissional durante a consulta e exame quanto pelo desconforto e disforia de gênero, levando assim à baixa adesão ao serviço de saúde. Alguns artigos trazem ainda, em conseguinte a este ponto, a preferência de alguns usuários pela autocoleta.

Palavras-chave: transexuais; exame citopatológico; serviço de saúde.

Abstract: Cervical cancer is one of the most common cancer among those with the female reproductive system. However, it is preventable and treatable, but there is a difficulty in capturing the target audience as well as low adherence to screening at the appropriate periodicity even in the female cisgender population, with this difficulty being accentuated among transsexuals. For this reason, this article aimed to analyze the reality of the transsexual population, especially of trans men, seeking to identify their experiences, difficulties and needs regarding adherence to cytopathological examination for cervical cancer screening in Primary Care through an integrative review with search carried out in three databases: Scopus, ScienceDirect and PubMed, obtaining a sample of 8 articles for the composition of this study. The results showed that trans users look much less for the health service when compared to the heterosexual/cisgender public, both for the approach, management and lack of patient-professional relationship during the consultation and examination and for the discomfort and dysphoria of gender, thus leading to low adherence to the health service. Some articles also bring, to this point, the preference of some users for self-collection.

Keywords: transgender persons; cytopathological test; health care.

\footnotetext{
I Universidade Tiradentes (UNIT). E-mail: tavares.mota2012@hotmail.com

${ }^{2}$ Graduando em Enfermagem na Universidade Tiradentes (UNIT), Aracaju (SE), Brasil. E-mail: denissonandradee@gmail.com

3 Mestre em Ciências da Saúde pela Universidade Federal de Sergipe (UFS), Aracaju (SE), Brasil. E-mail: fercosmart@gmail.com

${ }^{4}$ Mestre em Biotecnologia Industrial pela Universidade Tiradentes (UNIT), Aracaju (SE), Brasil. E-mail: nanda-dantas@hotmail.com

${ }^{5}$ Graduanda em Enfermagem pela Universidade Tiradentes (UNIT), Aracaju (SE), Brasil. E-mail: leticiafreiregonzaga@gmail.com

${ }^{6}$ Graduanda em Enfermagem pela Universidade Tiradentes (UNIT), Aracaju (SE), Brasil. E-mail: lua.jem@gmail.com

7 Mestre em Saúde e Ambiente pela Universidade Tiradentes (UNIT), Aracaju (SE), Brasil. E-mail: tacianasilveirapassos@gmail.com
} 
Resumen: El cáncer de cuello uterino es uno de los cánceres más comunes entre quienes tienen el sistema reproductivo femenino. Sin embargo, es prevenible y tratable, pero existe una dificultad para captar la audiencia objetivo, así como una baja adherencia al cribado en la periodicidad adecuada incluso en la población femenina cisgénero, siendo esta dificultad acentuada entre las transexuales. Por ello, este artículo tuvo como objetivo analizar la realidad de la población transexual, especialmente de hombres trans, buscando identificar sus vivencias, dificultades y necesidades en cuanto a la adherencia al examen citopatológico para el cribado del cáncer de cuello uterino en Atención Primaria a través de una revisión integradora. con búsqueda realizada en tres bases de datos: Scopus, ScienceDirect y PubMed, obteniendo una muestra de 8 artículos para la composición de este estudio. Los resultados mostraron que los usuarios trans buscan mucho menos el servicio de salud en comparación con el público heterosexual / cisgénero, tanto por el abordaje, manejo y falta de relación paciente-profesional durante la consulta y exploración como por el malestar y disforia de género, lo que lleva a baja adherencia al servicio de salud. Algunos artículos también traen, hasta este punto, la preferencia de algunos usuarios por la autocolección.

Palabras clave: transexuales; examen citopatológico; servicio de salud.

\section{Introdução}

O início da história do chamado Movimento LGBT (Lésbicas, Gays, Bissexuais, Transexuais e Travestis) ocorreu em Nova lorque, em 1969, devido à maneira com que esse grupo era tratado pelas autoridades. No Brasil, essa luta começou um ano depois, em 1970, mesmo durante o período de regime militar, com reuniões em espaços sociais, como bares e clubes (QUERINO et al., 20I7).

Na década de 1980, surge a epidemia da Síndrome da Imunodeficiência Adquirida (Aids) e com ela a visibilidade negativa da comunidade LGBT aumentou, visto que os indivíduos homossexuais sofreram maior impacto epidemiológico e social (ROLIM et al., 2016). Devido ao preconceito que essa população enfrenta, muitas vezes suas necessidades de saúde não são contempladas, pois temem revelar sua orientação sexual, omitindo-se por vezes quando procuram o serviço de saúde, com o intuito de diminuir impactos negativos que possam surgir e comprometendo assim a sua assistência em saúde (SANTOS et al., 2020).

Com a redemocratização no país, em especial com a criação da Constituição Federal, em 1988, e a implementação do Sistema Único de Saúde (SUS) e com as Leis Orgânicas da Saúde n 8.080/90 e n 8.142/90, avanços começaram a ser alcançados. Posteriormente, foi criada a Política Nacional de Saúde Integral LGBT, instituída

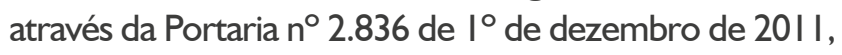
na busca de maior visibilidade e garantia de exerć́cio dos princípios básicos do SUS para a inclusão desses usuários aos serviços públicos de saúde (BRASIL, 20I I).

No entanto, o grupo trans - que abrange transgêneros, travestis e não binários - ainda é um tema complexo, pois desafia convenções sociais. Nesse sentido, é considerado transexual aquele que não se identifica com seu sexo biológico e/ou atribuições socioculturais impostas ao gênero deste (BARROS; LEMOS; AMBIEL,
2019). Ademais, a expectativa de vida dos transexuais é consideravelmente mais baixa do que a média geral populacional, sendo estimada em 35 anos de idade (SANTOS; SILVA; FERREIRA, 2019).

Diante das dificuldades que a população trans encontra, a aceitação do visual é uma das maiores, a qual faz muitos deles optarem por Cirurgias de Redesignação Sexual (CRS), que são realizadas para conquistar as modificações corporais desejadas (BOZZI; LIMA, 20I8). Atualmente, as CRS são ofertadas pelo SUS, no entanto, devido à alta demanda e ao acompanhamento pelo qual o indivíduo deve passar com psicólogo e psiquiatra por um período de dois anos há uma ampliação das barreiras ao acesso (MACIEL, 20I7).

Paralelamente a essa conjuntura, segundo a Organização Mundial de Saúde (OMS), o câncer de colo de útero é o quarto mais comum no mundo, com cerca de 570 mil novos casos, em 20 18. Especificamente na América Latina e Caribe, a Organização Pan-Americana da Saúde (OPAS) declarou que, por ano, mais de 56 mil mulheres são diagnosticadas com este câncer, das quais mais de 28 mil perdem suas vidas por conta da doença, sendo este $\circ$ $3^{\circ}$ tipo de câncer que mais acomete mulheres nessa localização. Ademais, o Instituto Nacional de Câncer (INCA) estima que ocorram 16.590 casos de câncer de colo de útero, em 2020, e em 2018, a média de número de óbitos foi de 6.596 (INSTITUTO NACIONAL DE CÂNCER JOSÉ ALENCAR GOMES DA SILVA, 2020).

Este câncer é, no entanto, prevenível e apresenta tratamento. Em nível de Brasil, o Ministério da Saúde implementou no calendário vacinal, em 2014, a vacina tetravalente contra o Papilomavírus Humano (HPV), que promove proteção contra os sorotipos $6,11,16$ e 18, sendo os dois últimos responsáveis por cerca de $70 \%$ dos casos de câncer do colo do útero. Outrossim, o exame preventivo complementa a ação de prevenção do agravo em questão, devendo ter sua realização e rastreamento 
iniciados a partir dos 25 anos de idade (INSTITUTO NACIONAL DE CÂNCER JOSÉ ALENCAR GOMES DA SILVA, 2020).

Nesse contexto, a Atenção Primária à Saúde (APS) é fundamental, não só para captação do público-alvo, como também para a promoção de educação em saúde e divulgação de informações de qualidade para auxílio da conscientização populacional. Dessa forma, este estudo objetiva identificar as experiências, dificuldades e necessidades dos homens trans quanto à adesão ao exame citopatológico para rastreamento do câncer de colo de útero na Atenção Primária. A inexistência de publicações brasileiras e da discussão da temática na vivência acadêmica viabilizou a pesquisa de estudos internacionais sobre esta questão.

\section{Metodologia}

O presente estudo trata-se de uma revisão integrativa, a qual possui finalidade de sintetizar múltiplos estudos publicados, indicando lacunas a serem preenchidas no conhecimento através de novas pesquisas. Ademais, possibilita conclusões gerais sobre uma área específica, o que gera novos conhecimentos pautados nos resultados encontrados (SOARES, 20I4).
A revisão integrativa tem seis fases distintas, iniciando pelaidentificação do temae eleleção da hipótese para elaboração da pesquisa, seguida do estabelecimento dos critérios de inclusão e exclusão da amostragem para assim categorizar os estudos selecionados. Posteriormente, realiza-se uma avaliação dos estudos incluídos para posterior interpretação dos resultados, seguida da apresentação da síntese do conhecimento (SOUSA et al., 2017).

O levantamento dos artigos selecionados foi por meio das bases de dados: Scopus, ScienceDirect e PubMed. Através da utilização dos descritores: transgender persons; uterine neoplasms; primary health care, subsidiados pelo operador booleano "AND", encontrou-se 32 artigos. A mesma estratégia foi utilizada em português, mas não foram encontradas publicações.

Adotou-se como critérios de inclusão: artigos publicados entre os anos de 2015-2020, nos idiomas português e inglês. Já os critérios de exclusão foram: produções científicas em formatos de teses, trabalhos de conclusão de curso, monografias, resumos expandidos, artigos em duplicata e capítulos de livros. Após aplicar esses filtros e critérios de seleção, a amostra da presente revisão integrativa foi composta por oito artigos, conforme diagrama abaixo (Figura I).

Figura I - Diagrama da busca de artigos para a presente revisão integrativa

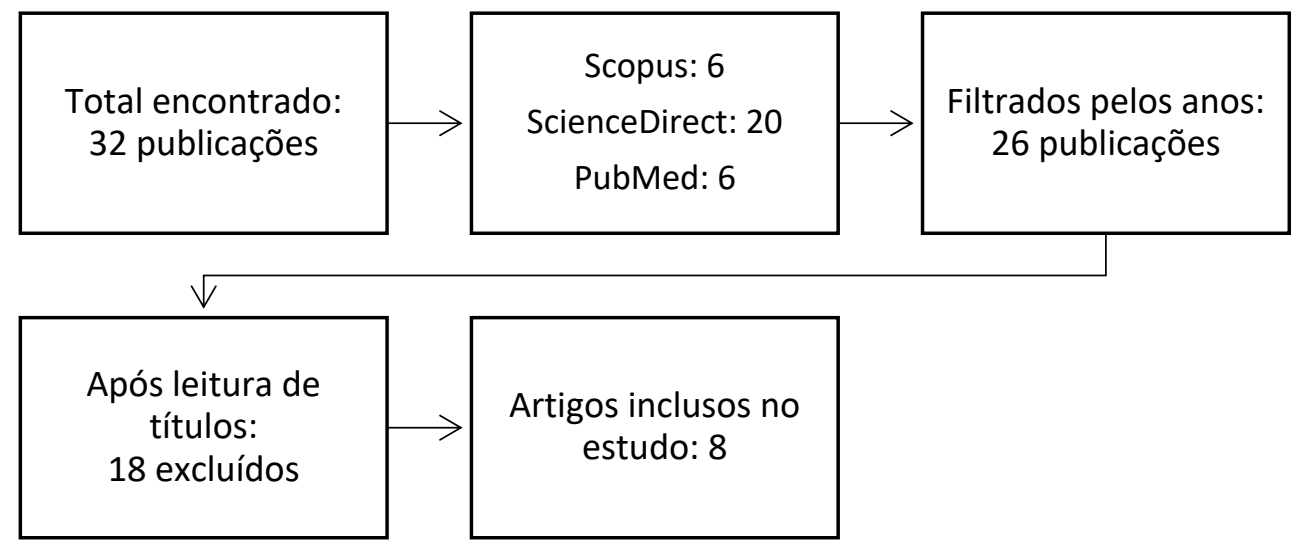

Fonte: elaborada pelos autores (2020).

Prontamente, esses estudos foram avaliados criteriosamente a fim de utilizar aqueles que melhor abordam o tema proposto, sendo os artigos selecionados tabulados com as seguintes variáveis: título, autor, ano, objetivo, resultados e classificação do nível de evidência (Quadro I).

A classificação do nível de evidência dos artigos selecionados foi realizada, sendo obedecida a hierarquia de evidências ( I a 6) conforme o delineamento das pesquisas para uma melhor análise crítica dos artigos. Assim, foram aplicados os critérios da Agency for Healthcare and Research and Quality de acordo com os seis níveis de evidências: (I) revisão sistemática ou metanálise; (II) ensaios clínicos randomizados; (III) ensaios clínicos sem randomização; (IV) estudos de coorte e de caso-controle; (V) revisão sistemática de estudos descritivos e qualitativos e (VI) único estudo descritivo ou qualitativo.

\section{Resultados e discussão}

Os oito artigos selecionados (Quadro I) apresentam-se no idioma inglês e foram predominantemente estudos do Canadá e Estados Unidos, nos quais foi possível encontrar dados extremamente relevantes e de suma importância para a construção do presente artigo. 


\begin{tabular}{|c|c|c|c|c|c|}
\hline Título & Autor & Ano & Objetivo & Resultados & $\begin{array}{l}\text { Nível de } \\
\text { evidência }\end{array}$ \\
\hline $\begin{array}{l}\text { Cancer screening rates } \\
\text { among transgender adults: } \\
\text { cross-sectional analysis of primary } \\
\text { care data }\end{array}$ & KIRAN et al. & 2019 & $\begin{array}{l}\text { Comparar as taxas de } \\
\text { rastreamento do câncer cervical, } \\
\text { de mama e colorretal entre } \\
\text { pacientes que são transgêneros } \\
\text { e aqueles que são cisgêneros (ou } \\
\text { seja, não transgêneros). }\end{array}$ & $\begin{array}{l}\text { Um total de I } 20 \text { pacientes transgêneros foram } \\
\text { identificados como elegíveis para rastreamento de } \\
\text { câncer. Estes eram menos prováveis que pacientes } \\
\text { cisgêneros ( } n=20.5 \text { I } 4 \text { ) para rastreamento de } \\
\text { câncer cervical ( } 56 \% \text { vs } 72 \%) \text {; mama ( } 33 \% \text { vs } 65 \%) \\
\text { e colorretal ( } 55 \% \text { vs } 70 \%) \text {. }\end{array}$ & VI \\
\hline $\begin{array}{l}\text { Cervical Cancer Screening } \\
\text { Preferences Among Trans- } \\
\text { Masculine Individuals: Patient- } \\
\text { Collected Human Papillomavirus } \\
\text { Vaginal Swabs Versus Provider- } \\
\text { Administered Pap Tests }\end{array}$ & $\begin{array}{l}\text { MCDOWELL } \\
\text { et al. }\end{array}$ & 2017 & $\begin{array}{l}\text { Elucidar as preferências de } \\
\text { rastreamento do câncer cervical } \\
\text { entre indivíduos trans masculinos. }\end{array}$ & $\begin{array}{l}\text { A maioria dos homens trans ( } 94 \% \text { pessoalmente } \\
\text { e } 91 \% \text { on-line) preferiu o esfregaço de HPV } \\
\text { frontal autocoletado ao exame de Papanicolau. } \\
\text { Os participantes perceberam que os swabs coletados } \\
\text { por eles próprios eram menos invasivos, provocavam } \\
\text { menos disforia de gênero e promoviam um maior } \\
\text { senso de agência. Por outro lado, alguns participantes } \\
\text { ficaram preocupados com a precisão do esfregaço de } \\
\text { HPV em relação à autocoleta com swab; bem como } \\
\text { com o desconforto em se envolver com seus órgãos } \\
\text { genitais, os quais eles poderiam não querer reconhecer. } \\
\text { Aqueles que disseram ter relações positivas com o } \\
\text { profissional relataram serem mais aceitáveis os exames } \\
\text { de Papanicolau coletados pelo profissional. }\end{array}$ & $\mathrm{VI}$ \\
\hline $\begin{array}{l}\text { Understanding Transgender Men's } \\
\text { Experiences with and Preferences } \\
\text { for Cervical Cancer Screening: } \\
\text { A Rapid Assessment Survey }\end{array}$ & SEAY et al. & 2017 & $\begin{array}{l}\text { Compreender as experiências e } \\
\text { preferências para o rastreamento } \\
\text { do câncer cervical entre homens } \\
\text { transexuais. }\end{array}$ & $\begin{array}{l}\text { Metade }(50,5 \%) \text { dos participantes não fez exame } \\
\text { Papanicolau nos últimos } 3 \text { anos. A maioria }(57,1 \%) \\
\text { dos participantes preferiu a autocoleta ao invés } \\
\text { do exame coletado pelo profissional. Participantes } \\
\text { que relataram discriminação eram mais propensos } \\
\text { a preferir a autocoleta para HPV. }\end{array}$ & VI \\
\hline
\end{tabular}




\begin{tabular}{|c|c|c|c|c|c|}
\hline Título & Autor & Ano & Objetivo & Resultados & $\begin{array}{l}\text { Nível de } \\
\text { evidência }\end{array}$ \\
\hline $\begin{array}{l}\text { Test performance and } \\
\text { acceptability of self versus } \\
\text { provider-collected swabs for high- } \\
\text { risk HPV DNA testing in female- } \\
\text { to-male trans masculine patients }\end{array}$ & $\begin{array}{l}\text { REISNER } \\
\text { et al. }\end{array}$ & 2018 & $\begin{array}{l}\text { Avaliar o desempenho do teste } \\
\text { e aceitabilidade de amostras } \\
\text { vaginais autocoletadas em } \\
\text { comparação com esfregaços } \\
\text { cervicais coletados pelo } \\
\text { profissional de saúde para } \\
\text { detecção de DNA de hrHPV } \\
\text { em indivíduos trans masculinos } \\
\text { entre } 21 \text { e } 64 \text { anos de idade. }\end{array}$ & $\begin{array}{l}\text { Dos I } 3 \text { I participantes que completaram os testes de } \\
\text { HPV coletados por eles mesmos e pelo profissional, } \\
2 \text { I casos de hrHPV foram detectados pelo profissional } \\
\text { com o esfregaço cervical (padrão-ouro; I6,0\% } \\
\text { de prevalência de hrHPV); I } 5 \text { desses casos foram } \\
\text { detectados com precisão pelo esfregaço vaginal } \\
\text { autocoletado. Em comparação com a amostra de DNA } \\
\text { de hrHPV cervical coletada pelo profissional (padrão } \\
\text { ouro), o teste de DNA de hrHPV vaginal demonstrou } \\
\text { uma sensibilidade de } 7 \text { I,4\% e especificidade de } \\
98,2 \% \text {. Mais de } 90 \% \text { dos participantes mostraram } \\
\text { preferência pelo esfregaço vaginal autocoletado. }\end{array}$ & II \\
\hline $\begin{array}{l}\text { Cervical Cancer Screening for } \\
\text { Patients on the Female-to-Male } \\
\text { Spectrum: a Narrative Review and } \\
\text { Guide for Clinicians }\end{array}$ & $\begin{array}{l}\text { POTTER } \\
\text { et al. }\end{array}$ & 2015 & $\begin{array}{l}\text { Orientar o rastreamento do câncer } \\
\text { cervical para pacientes no espectro } \\
\text { feminino - masculino (FTM). }\end{array}$ & $\begin{array}{l}\text { Os relatos do artigo trazem as barreiras encontradas } \\
\text { pela população FTM, sejam elas físicas e/ou emocionais } \\
\text { e o quanto os profissionais da saúde ainda não sabem } \\
\text { fazer o manejo correto com esses pacientes. }\end{array}$ & V \\
\hline $\begin{array}{l}\text { Cancer and Lesbian, Gay, } \\
\text { Bisexual, Transgender/ } \\
\text { Transsexual, and Queer/ } \\
\text { Questioning (LGBTQ) Populations }\end{array}$ & $\begin{array}{l}\text { QUINN } \\
\text { et al. }\end{array}$ & 2015 & $\begin{array}{l}\text { Revisar os fatores associados ao } \\
\text { risco de doenças a população } \\
\text { LGBTQ na prevenção primária, } \\
\text { secundária e terciária. }\end{array}$ & $\begin{array}{l}\text { O câncer de mama se mostra em potencial para grupos } \\
\text { de homens transexuais principalmente quando não se } \\
\text { submetem a mastectomia total. O rastreio de câncer } \\
\text { de próstata em pacientes mulheres trans deve ser } \\
\text { efetivo mesmo àqueles que se submeteram à cirurgia } \\
\text { de redesignação, pois não diminui as chances de } \\
\text { desenvolvimento da doença. Um ponto relevante é sob } \\
\text { a problemática em identificar esses grupos e assim } \\
\text { deixar uma lacuna aberta na procura dessas pessoas } \\
\text { pelo serviço de saúde, por não se sentirem seguras. }\end{array}$ & $\mathrm{VI}$ \\
\hline
\end{tabular}


(conclusão)

\begin{tabular}{|c|c|c|c|c|c|}
\hline Título & Autor & Ano & Objetivo & Resultados & $\begin{array}{l}\text { Nível de } \\
\text { evidência }\end{array}$ \\
\hline $\begin{array}{l}\text { Gynecologic cancer screening in } \\
\text { the transgender male population } \\
\text { and its current challenges }\end{array}$ & PATEL et al. & 2019 & $\begin{array}{l}\text { Examinar o rastreamento de câncer } \\
\text { (mama, colo do útero) e suas } \\
\text { barreiras para a população trans. }\end{array}$ & $\begin{array}{l}\text { O câncer de mama na população trans não está } \\
\text { bem definido, porém os que não se submetem } \\
\text { a mastectomia têm chances semelhantes às } \\
\text { mulheres cisgêneros de uma a cada oito mulheres. } \\
\text { A incidência de câncer endometrial é desconhecida } \\
\text { e a histerectomia de rotina como forma preventiva } \\
\text { não é recomendada, segundo o American College } \\
\text { of Obstetrics and Gynecologists (ACOG). Em relação } \\
\text { ao câncer cervical foi realizada a Pesquisa Nacional } \\
\text { de Transgêneros na qual trouxe que apenas } 27 \% \\
\text { da população trans que ainda tem colo do útero } \\
\text { relataram que tinham feito o exame de Papanicolau, } \\
\text { tendo relatos de que alguns não realizaram devido } \\
\text { à abordagem na realização do exame e da maneira } \\
\text { como foi realizado. }\end{array}$ & VI \\
\hline $\begin{array}{l}\text { Unique Primary Care Needs of } \\
\text { Transgender and Gender Non- } \\
\text { Binary People }\end{array}$ & NISLY et al. & 2018 & $\begin{array}{l}\text { Destacar alguns elementos que } \\
\text { são essenciais para criar um } \\
\text { ambiente seguro e acolhedor } \\
\text { em sua prática para pessoas } \\
\text { transgênero e não binárias. }\end{array}$ & $\begin{array}{l}\text { O homem trans, quando sem qualquer tipo de } \\
\text { cirurgia, deve realizar todos os exames necessários } \\
\text { para rastreio de câncer de colo de útero, mamografia, } \\
\text { entre outros. A forma como esse paciente é abordado } \\
\text { e acolhido na realização dos exames se mostra como } \\
\text { fonte precursora da continuidade em realizar seus } \\
\text { exames de rotina, mostra que o treinamento da equipe } \\
\text { no que diz respeito a confidencialidade e proteção } \\
\text { a essa pessoa é importante. Outro ponto é o rastreio } \\
\text { de Infecções Sexualmente Transmissíveis (ISTs) visto } \\
\text { que é comum encontrar nessa população determinadas } \\
\text { doenças como a vaginose bacteriana. }\end{array}$ & $\mathrm{VI}$ \\
\hline
\end{tabular}

Fonte: elaborado pelas autoras (2020). 
Em síntese, os transgêneros foram identificados como elegíveis para o rastreamento de câncer, representando, no estudo de Kiran e outros (2019), um total de 120 pacientes que, quando comparados à população cisgênero, percebeu-se significativa diferença na adesão ao rastreio, sendo esta diferente de acordo com os tipos de cânceres: cervical (56\% trans vs $72 \%$ cis); mama (33\% trans vs $65 \%$ cis) e colorretal (55\% trans vs $70 \%$ cis).

Estudos como o de Quinn e outros (2015) revelam que esse aumento acontece principalmente quando os homens transexuais não realizam a mastectomia total, bem como em mulheres trans que se submeteram a cirurgia de redesignação sexual, visto que as chances de desenvolvimento da doença nesse caso não diminuem após o procedimento cirúrgico.

Essa problemática mostra-se crescente e, através do estudo de Patel e outros (2019), essa reafirmação é ainda mais forte quando aponta que os transgêneros têm chances semelhantes às das mulheres cisgênero com estatísticas de que uma a cada oito poderão desenvolver câncer de mama. Ainda neste estudo, apenas $27 \%$ da população trans que ainda tem colo do útero relata que realiza o exame Papanicolau.

Em conseguinte a essa explanação, o estudo de Seay e outros (2017), traz que $57,1 \%$ dos seus participantes preferiram a autocoleta cervical devido à situações anteriores de discriminação por parte de profissionais para com eles. Reisner e outros (20I8) referem que, dos I3I pacientes atendidos, $90 \%$ preferiam a autocoleta.

Para tal, estudos como o de Nisly e outros (20I8) são importantes, pois enfatizam a relevância da realização de todos os exames necessários para o rastreio de câncer, principalmente por aqueles que não se submeteram a nenhum tipo de cirurgia, sendo o foco deste trabalho.

Considerado um dos cânceres mais incidentes em pessoas que apresentam 0 aparelho sexual feminino, o câncer de colo de útero está intimamente ligado a determinantes comportamentais, fatores de risco e detecção tardia, sendo, no entanto, prevenível e tratável quando com o rastreamento adequado (REISNER et al., 20I8).

Segundo o Ministério da Saúde, atingir alta cobertura no rastreamento da população alvo é o fator mais importante para obter redução significativa da incidência e da mortalidade por câncer cervical, preconizando o início do rastreamento a partir dos 25 anos de idade com vida sexual ativa. No entanto, mesmo as mulheres cisgênero são de difícil captação para tal (BRASIL, 20I6).

Devido à baixa expectativa de vida da população transexual interligada a maiores riscos de saúde em decorrência de fatores como consequências de modificações corporais sem orientação médica, uso de substâncias, ISTs, bullying, rejeição, ansiedade, depressão, suicídio, entre outros (SANTOS; SILVA; FERREIRA, 2019), faz-se necessário uma atenção individualizada aos homens trans para que estes não continuem marginalizados nos serviços de saúde e participem do grupo de rastreio para câncer cervical. Destarte, o Quadro I traz artigos que evidenciam a importância de tal, bem como as dificuldades e preferências destes usuários.

Nesse aspecto, parte dos estudos utilizados apontou que uma parcela significativa da população alvo não realiza o rastreamento do câncer de colo de útero na periodicidade preconizada, sendo este inferior quando comparado aos números da população cisgênero feminina (KIRAN et al., 2019; PATEL et al., 2019; SEAY et al., 2017). Outros estudos revelam também que há um déficit na relação entre os usuários trans e os profissionais de saúde, o que resulta na manutenção do estigma e baixa adesão aos serviços de saúde (NISLY et al., 20I8; POTTER et al., 20I5).

Desse modo, os artigos chegam a denominadores comuns considerados influenciadores nesta situação além da relação paciente-profissional já citada acima sendo eles: desconforto com o procedimento invasivo, disforia de gênero acentuada e discriminação (MCDOWELL et al., 2017; SEAY et al., 20I7). Concomitantemente aos autores citados neste parágrafo Reisner e outros (2018), realizaram seu estudo para comparar resultados físicos, emocionais e citológicos entre a técnica de coleta cervical pelo profissional e pelo próprio paciente.

Foi encontrada, entre os usuários participantes, uma preferência pela autocoleta, a qual mostrou resultados citológicos relativamente semelhantes à coleta pelo profissional em Reisner e outros (2018), bem como favoreceu a diminuição dos fatores de baixa adesão e, em especial, contribuiu para o aumento do senso de agência. Por outro lado, alguns pacientes ficaram preocupados com a eficácia da autocoleta e relataram preferir o Papanicolau com o profissional desde que exista uma boa relação entre ambos (MCDOWELL et al., 2017).

Na metanálise de Petignat e colaboradores (2007), foram avaliados 66 estudos de relevância para sua pesquisa, sendo nestes as amostras coletadas através de tampão autoinserido ou cotonete vaginal com o DNA do HPV detectado por uma variedade de cadeias de polimerases. Os resultados desse estudo corroboram com aqueles encontrados nos artigos anteriormente citados, trazendo uma média de 4, $1 \%$ de todas as diferenças absolutas entre as taxas de detecção através da autocoleta e coleta médica, confirmando assim, que a autocoleta é tão sensível quanto a amostragem coletada pelo profissional, método este que pode ser alternativa para o público trans.

Diante do exposto, observa-se que um dos grandes desafios para o rastreamento do câncer de colo de útero em homens transexuais advém da estigmatização e despreparo mantidos por alguns profissionais, deixando assim uma lacuna na procura dessas pessoas pelo serviço de saúde. Além disso, há os fatores físicos e emocionais dos usuários, os quais precisam ser levados em consideração 
de modo singular e humanizado (NISLY et al., 2018; QUINN et al., 2015).

Ainda, segundo Rosa e colaboradores (2019), falta educação, conhecimento e competência por parte dos profissionais de saúde para com a população trans, sendo primordial para solucionar esta falta o aumento e/ou inclusão de conteúdos sobre a diversidade LGBT + nas grades curriculares dos cursos da área. Inclusive, com a abordagem desse conteúdo na academia há maiores chances de implementação de educação permanente nos serviços de saúde, contribuindo assim para o cumprimento do papel de educador em saúde do enfermeiro, bem como dos demais profissionais, e implementação de busca ativa acerca do perfil da população adscrita (SILVA, 2019).

\section{Considerações finais}

A adesão da população transexual para a realização do exame citopatológico e, consequentemente, ao rastreamento do câncer de colo de útero mostra-se um ponto crucial a ser discutido e estudado devido à baixa procura pelo serviço e à escassez de estudos realizados.

Evidencia-se que fatores relevantes para solidificação das políticas públicas já existentes bem como a implementação de novos métodos e melhorias junto ao manejo com esses pacientes são pontos importantes na adesão dessa população à realização dos exames e na procura pelos serviços de atenção primária à saúde. Vale salientar que, muitas vezes, a baixa adesão desses usuários, como já discutido neste trabalho, se dá pelo manejo para com eles durante sua procura aos serviços, como também pela falta de informação e sobre a importância de estar bem informado e de manter seus exames em dia.

Para tal, a produção de novos estudos sobre a população trans e as dificuldades encontradas por ela e por profissionais da saúde é significativamente considerável para o alcance de melhorias no serviço, assim como da adesão à realização dos exames necessários e o sentimento de respeito e cuidado integral para consigo advindo dos profissionais que estejam à frente do serviço de saúde.

\section{Referências}

BARROS, L. O.; LEMOS, C. R. B.; AMBIEL, R. A. M. Qualidade de vida e satisfação com a imagem corporal de transexuais. Arquivos Brasileiros de Psicologia, Rio de Janeiro, v. 7I, n. I, jan./abr. 2019.

BOZZI F.; LIMA F. M. Procedimento de redesignação dos transexuais sob a ótica dos direitos humanos. In: SEMINÁRIO INTERNACIONAL DE DIREITOS HUMANOS E DEMOCRACIA, 5., 20I8, ljuí. Anais [...]. ljuí: Unijuí, 2018. Disponível em: https:// publicacoeseventos.unijui.edu.br/index.php/ direitoshumanosedemocracia/article/view/9045. Acesso em: 20 out. 2020.

BRASIL. [Constituição (1988)]. Constituição da República Federativa do Brasil. Brasília, DF: Senado Federal, 1988.

BRASIL. Lei $n^{\circ} 8.080$, de 19 de setembro de 1990. Lei Orgânica da Saúde. Dispõe sobre as condições para a promoção, proteção e recuperação da saúde, a organização e o funcionamento dos serviços correspondentes e dá outras providências. Diário Oficial da União, Brasília, DF, set. 1990.

BRASIL. Lei $n^{\circ} 8.142$, de 28 de dezembro de 1990. Dispõe sobre a participação da comunidade na gestão do Sistema Único de Saúde (SUS) e sobre as transferências intergovernamentais de recursos financeiros na área da saúde e dá outras providências. Diário Oficial da União, Brasília, DF, 3I dez. 1990.

BRASIL. Ministério da Saúde. Portaria $n^{\circ} 2.836$, de $1^{\circ}$ de dezembro de $201 \mathrm{I}$. Institui no âmbito do Sistema Único de Saúde (SUS), a Política Nacional de Saúde Integral de Lésbicas, Gays, Bissexuais, Travestis e Transexuais (Política Nacional de Saúde Integral LGBT). Diário Oficial da União, Brasília, DF, 02 dez. 201 I.

INSTITUTO NACIONAL DE CÂNCER JOSÉ ALENCAR GOMES DA SILVA. Diretrizes brasileiras para o rastreamento do câncer do colo do útero. 2. ed. Rio de Janeiro: INCA, 2016. p. 32-35.

INSTITUTO NACIONAL DE CÂNCER JOSÉ ALENCAR GOMES DA SILVA. Parâmetros técnicos para o rastreamento do câncer do colo do útero. Rio de Janeiro: INCA, 2019. p. 22-23. 
INSTITUTO NACIONAL DE CÂNCER JOSÉ ALENCAR GOMES DA SILVA. Tipos de câncer: câncer do colo do útero. Rio de Janeiro: INCA, 2020. Disponível em: https://www.inca.gov. $\mathrm{br} /$ tipos-de-cancer/cancer-do-colo-do-utero. Acesso em: 19 set. 2020.

\section{INSTITUTO SÍRIO-LIBANÊS DE ENSINO} E PESQUISA. Protocolos da atenção básica: saúde das mulheres. Brasília, DF: Instituto Sírio-Libanês de Ensino e Pesquisa, 2016.

KIRAN, T. et al. Cancer screening rates among transgender adults: cross-sectional analysis of primary care data. Canadian Family Physician. Don Mills, v. 65, n. I, p. e-30-e-37, Jan. 2019.

MACIEL, I. M. Panorama brasileiro do processo transexualizador no âmbito do SUS. 2017. Monografia (Graduação em Medicina) Universidade Federal da Bahia, Salvador, 2017.

MCDOWELL, M. et al. Cervical Cancer

Screening Preferences Among Trans-Masculine Individuals: Patient-Collected Human Papillomavirus Vaginal Swabs Versus ProviderAdministered Pap Tests. LGBT Health. v. 4, n. 4, p. 252-259, Aug. 2017.

NISLY, N. L. et al. Unique Primary Care Needs of Transgender and Gender Non-Binary People. Clinical Obstetrics and Gynecology, lowa, v. 6I, n. 4, p. 674-686, Dec. 2018.

\section{ORGANIZAÇÃO PANAMERICANA DA SAÚDE.} Câncer de colo do útero é $3^{\circ}$ mais comum entre mulheres na América Latina e Caribe, mas pode ser prevenido. Brasília, DF: 2019. Disponível em: https://www.paho.org/pt/noticias/I-2-20I9cancer-colo-do-utero-e-3o-mais-comum-entremulheres-na-america-latina-e-caribe? page $=\mathrm{I}$.

Acesso em: 19 set. 2020.

PATEL, J. M. et al. Gynecologic cancer screening in the transgender male population and its current challenges. Maturitas, Limerick, v. I29, p. 40-44, Nov. 2019.

PETIGNAT, P. et al. Are self-collected samples comparable to physician-collected cervical specimens for human papillomavirus DNA testing? A systematic review and meta-analysis. Gynecologic Oncology, v. 105, n. 2, p. 530-535, May, 2007.
POTTER, J. et al. Cervical Cancer Screening for Patients on the Female-to-Male Spectrum: a Narrative Review and Guide for Clinicians. Journal of General Internal Medicine, Seccaucus, v. 30. n. 12. p. 1857-1864, Dec. 2015.

QUERINO, M. S. et al. Ações da equipe de enfermagem na implementação da política de lésbicas, gays, bissexuais, travestis e transexuais - revisão de literatura. Revisa - Revista de Divulgação Científica Sena Aires, Goiás, v. 6, n. I, p. 46-58, 2017.

QUINN, G. P. et al. Cancer and Lesbian, Gay, Bisexual, Transgender/ Transsexual, and Queer/ Questioning (LGBTQ) Populations. CA: a Cancer Journal for Clinicians, Hoboken, v. 65, n. 5, p. 384-400, Sept. 2015.

REISNER, S. L. et al. Test performance and acceptability of selfversus provider-collected swabs for high-risk HPV DNA testing in femaleto-male trans masculine patients. PLOS ONE, v. 13, n. 3,2018 .

ROLIM, A. G. F. et al. A realidade de um serviço de média complexidade, para o público LGBT, voltado para a atenção à saúde sexual e reprodutiva da população: do ideal ao real. EXTRAMUROS - Revista de Extensão da UNIVASF, Petrolina, v. 4, n. 2, 2016.

ROSA, D. F. et al. Assistência de Enfermagem à população trans: gêneros na perspectiva da prática profissional. Revista Brasileira de Enfermagem. Brasília, v. 72. Supl. I, jan/fev. 2019.

SANTOS, L. E. S. et al. O acesso ao Sistema Único de Saúde na percepção de homossexuais masculinos. Revista Brasileira de Enfermagem, Brasília, v. 73, n. 2, mar. 2020.

SANTOS, J. S.; SILVA, R. N.; FERREIRA, M. A. Saúde da População LGBTI + na Atenção Primária à Saúde e a Inserção da Enfermagem. Escola Anna Nery, Rio de Janeiro, v. 23, n. 4. out. 2019.

SEAY, J. et al. Understanding Transgender Men's Experiences with and Preferences for Cervical Cancer Screening: A Rapid Assessment Survey. LGBT Health, New Rochelle, v. 4. n. 4, Aug. 2017. 
SILVA, A. S. M. Reflexões sobre a Política Nacional de Saúde Integral de LGBT: percepção de enfermeiros que atuam na atenção primária à saúde. Monografia (Graduação em Enfermagem) - Escola Superior de Ciências da Saúde, Brasília, 2019.

SOARES, C. B. et al. Revisão Integrativa:

conceitos e métodos utilizados na enfermagem.

Revista da Escola de Enfermagem da USP,

São Paulo, v. 48, n. 2, p. 335-345, 2014.

SOUSA, L. M. M. et al. A metodologia de revisão integrativa da literatura em enfermagem. Revista Investigação em Enfermagem, v. 2, n. 21 , p. 17-26, nov. 2017. 